\title{
PERAN PERAWAT DALAM MENINGKATKAN KEBERSIHAN GIGI DAN MULUT ANAK TUNAGRAHITA
}

\author{
THE ROLE OF CAREGIVER IN IMPROVING ORAL HEALTH FOR CHILDREN WITH \\ INTELLECTUAL DISABILITY DEVELOPMENT \\ Dyah Nawang Palupi, Ranny Rachmawati, Zamidha Octarina Anggraini \\ Program Studi Pendidikan Dokter Gigi, Fakultas Kedokteran Gigi Universitas Brawijaya \\ Jl. Veteran Malang 65145 \\ E-mail: dyah.nawang@gmail.com
}

\begin{abstract}
ABSTRAK
Latar belakang: Pengetahuan tentang kebersihan gigi dan mulut dan keterampilan menyikat gigi yang baik dan benar pada anak tuna grahita masih kurang sekalipun anak tunagrahita ringan memiliki tingkat kecerdasan lebih tinggi dari pada derajat retardasi yang lain. Anak tuna grahita membutuhkan perawat untuk membantu menjaga kebersihan gigi dan mulut. Perilaku adaptif diperlukan anak tuna grahita ringan untuk meningkatkan kesehatan gigi dan mulut.

Tujuan: untuk mengetahui peran perawat anak tunagrahita dalam meningkatkan kesehatan gigi dan mulut anak tunagrahita

Metode: pra-eksperimental dengan rancangan penelitian One Group Pretest Posttest. Sampel penelitian adalah anak dengan IQ 69-55 menurut skala Weschler (WISC) $(n=30)$ dan perawat tunagrahita $(n=18)$. Check list digunakan pada perawat tunagrahita setelah dilakukan penyuluhan teknik menyikat untuk mengukur perubahan keterampilan menyikat gigi dan pengukuran $\mathrm{OHI-s}$ anak tuna grahita ringan.

Hasil penelitian: terdapat penurunan $\mathrm{OHI}$-s anak tunagrahita sebelum dan sesudah penyuluhan pada perawat tunagrahita.

Kesimpulan: penyuluhan pada perawat tunagrahita efektif dalam meningkatkan kebersihan mulut anak tunagrahita ringan yang ditandai dengan turunnya nilai $\mathrm{OHI}-\mathrm{s}$ anak tunagrahita ringan sesudah diberikan penyuluhan cara menyikat gigi oleh perawat.
\end{abstract}

Kata kunci: perawat, anak tunagrahita, OHI-s. 


\begin{abstract}
Background: Intellectual and Development Dissability (IDD) have a low knowledge about oral hygiene and less skill in toothbrushing, although they have higher intelligence level than other retardation levels. They need a caregiver to help them to keep their oral hygiene good. The adaptive behavior is needed in IDC to increase the oral health.

Objective: The purpose of this study was to find out the role of caregiver in improving oral health for children with IDD

Method: pra-experimental method with the research design is one group pretest and posttest. Data were collected from children with IQ 69-55 based on Weschler scale (WISC) in SLB Bhakti Luhur Malang's dormitory $(n=30)$ and caregivers $(n=18)$. The checklist were given to caregiver to measure the skill changes after the brushing teeth technique education has done and measure Oral Hygiene Indexsimplified (OHI-s) of IDD.

Result: there is a decreasing score OHI-s IDD before and after oral health education to their caregiver. Conclusion: There is an important role of caregiver in improving oral health children with IDD. The education of toothbrushing technique to caregiver is effective in increasing oral hygiene of IDD which is marked by decreasing of OHI-s score before and after education.
\end{abstract}

Key word: caregiver, chidren with Intellectual and Development Dissability (IDD), OHI-s 


\section{PENDAHULUAN}

Kesehatan gigi dan mulut masyarakat Indonesia masih merupakan hal yang perlu mendapat perhatian serius dari tenaga kesehatan, baik dokter maupun perawat gigi. Hal ini terlihat bahwa penyakit gigi dan mulut masih diderita oleh $90 \%$ penduduk Indonesia. Penyakit gigi dan mulut yang banyak diderita masyarakat di Indonesia adalah penyakit jaringan penyangga gigi dan karies gigi. Sumber dari kedua penyakit tersebut akibat kurangnya kebersihan gigi dan mulut, sehingga terjadilah akumulasi plak. Plak didefinisikan sebagai suatu lapisan tipis yang melekat erat di permukaan gigi. Plak didefinisikan sebagai suatu zat yang mengandung kumpulan bakteri yang terbentuk dari glikoprotein dan polisakarida ekstraselular ${ }^{1}$.

Kegiatan menyikat gigi adalah kegiatan preventif dalam menjaga kesehatan gigi dan mulut yang paling mudah dan murah dilakukan. American Dental Association menyarankan untuk menyikat gigi dua kali sehari, yaitu pada pagi hari setelah sarapan dan malam hari sebelum tidur ${ }^{2}$. Menyikat gigi selama dua menit dapat menurunkan plak hingga $41 \% .^{3}$ Keberhasilan pemeliharaan kesehatan gigi dan mulut dipengaruhi oleh faktor penggunaan alat, metode penyikatan, lama penyikatan, serta frekuensi dan waktu penyikatan yang tepat. ${ }^{4,5}$

Masalah perkembangan individu sejak dilahirkan, masa kanak-kanak, remaja hingga dewasa merupakan masalah yang menarik untuk disimak. Masa kanak-kanak merupakan masa yang sangat menentukan dalam tumbuh kembang seorang individu. Kebutuhan akan nutrisi yang cukup dan seimbang, pendidikan dan kesehatan merupakan modal mereka untuk dapat mencapai taraf perkembangan yang optimal. Ada anak yang lahir dengan kelainan yang dibawa sejak dari kandungan, ada anak yang mendapat kelainan selama proses persalinan, dan ada juga yang mendapatkan kelainan pada masa balita. Anak-anak dengan kelainan ini tergolong anak berkebutuhan khusus. Anak-anak berkebutuhan khusus didefinisikan sebagai anak yang mempunyai penyimpangan dari kondisi rata-rata anak pada umumnya baik secara fisik, mental maupun salah satu perilaku sosialnya. ${ }^{6,8} \quad$ Anak dengan kemampuan mental di bawah rata-rata dikenal dengan tuna grahita (Intellectual and Development Dissability atau IDD). ${ }^{7,8,9}$ Anak tunagrahita, diidentifikasi memiliki tingkat kecerdasan yang sedemikian rendahnya (di bawah normal) sehingga untuk meniti tugas perkembangannya memerlukan bantuan atau layanan secara khusus, terutama di dalamnya kebutuhan program pendidikan dan bimbingannya. ${ }^{6}$

Anak berkebutuhan khusus merupakan salah satu sumber daya manusia bangsa Indonesia yang kualitasnya harus ditingkatkan agar dapat berperan, tidak hanya sebagai obyek pembangunan tetapi juga sebagai subyek pembangunan. Anak penyandang cacat perlu dikenali dan diidentifikasi dari kelompok anak pada umumnya, karena mereka memerlukan pelayanan yang bersifat khusus, seperti pelayanan medik, pendidikan khusus maupun latihan tertentu yang bertujuan untuk mengurangi keterbatasan dan ketergantungan akibat kelainan yang diderita, serta 
menumbuhkan kemandirian hidup dalam masyarakat. ${ }^{10}$

Masalah kecacatan pada anak merupakan masalah yang cukup kompleks baik secara kuantitas maupun kualitas, mengingat berbagai jenis kecacatan mempunyai permasalahan tersendiri. Jika masalah anak penyandang cacat ini ditangani secara dini dengan baik dan keterampilan mereka ditingkatkan sesuai minat, maka beban keluarga, masyarakat dan negara dapat dikurangi. Sebaliknya jika tidak diatasi secara benar, maka dampaknya akan memperberat beban keluarga dan negara. ${ }^{11}$ Anak tunagrahita memiliki risiko yang lebih tinggi akan masalah kesehatan gigi dan mulut. Hal tersebut karena mereka memiliki kekurangan dan keterbatasan mental untuk melakukan pembersihan gigi sendiri yang optimal. Penyandang disabilitas memiliki masalah kesehatan dua kali lipat dibandingkan orang normal. ${ }^{12}$ Penelitian menunjukkan bahwa orang dengan tuna grahita lebih cenderung memiliki kebersihan mulut yang buruk dan penyakit periodontal dan mempunyai risiko memiliki karies lebih tinggi dibandingkan orang tanpa cacat intelektual. ${ }^{13}$

Menurut hasil Survey Sosial Ekonomi Nasional (Susenas) yang dilaksanakan Biro Pusat Statistik (BPS) tahun 2012, jumlah penyandang disabilitas di Indonesia sebanyak 6.008.661 orang. Dari jumlah tersebut sekitar 402.817 orang penyandang disabilitas intelektual atau tuna grahita. ${ }^{14}$ Sedangkan jumlah siswa baru di Sekolah Luar Biasa (SLB) tahun 2015/2016 sebesar 26.617 siswa, di mana 13.794 siswa $(51,8 \%)$ adalah siswa dengan tuna grahita. ${ }^{15}$ Perawatan gigi pada anak tunagrahita memerlukan pengertian, kesabaran dan pengalokasian waktu yang cukup agar dapat dibina kerjasama yang baik antara dokter gigi dan anak dengan tuna grahita, sekalipun hal ini dirasakan cukup sulit. Tingkat pengetahuan perawat tentang kesehatan gigi dan mulut sangat berpengaruh terhadap kebersihan gigi dan mulut anaknya. Perawat anak tunagrahita juga harus diberi nasehat untuk merawat kesehatan mulutnya, seperti cara dan penggunaan sikat gigi yang benar serta penggunaan pasta gigi berflouride pada anak maupun kontrol diet makanan. ${ }^{16}$ Kebersihan rongga mulut penting untuk dijaga agar tidak menimbulkan penyakit pada mulut dan gigi pada anak yang memiliki keterbelakangan mental terutama dalam menjaga kebersihan rongga mulutnya. Derajat kebersihan mulut dapat ditentukan dengan OHI-s. ${ }^{1}$

\section{METODE}

Desain penelitian yang digunakan pada penelitian ini adalah pra-eksperimental, yang bertujuan untuk mengetahui gejala atau pengaruh yang timbul sebagai akibat dari adanya perlakuan tertentu atau eksperimen tersebut. Rancangan penelitian One Group Pretest Postest Design digunakan pada penelitian ini karena rancangan ini juga tidak ada kelompok pembanding (kontrol), tetapi paling tidak sudah dilakukan observasi pertama (pretest) yang memungkinkan menguji perubahan-perubahan yang terjadi setelah adanya eksperimen (program). ${ }^{17}$ Upaya peningkatan kesehatan gigi dan mulut diukur sebelum dan sesudah diberikan perlakuan berupa penyuluhan kesehatan gigi 
dan mulut pada perawat tunagrahita dan pemeriksaan $\mathrm{OHI}$-s anak tunagrahita sebelum dan sesudah mendapat edukasi dari perawat tuna grahita. Edukasi yang diberikan perawat pada anak tunagrahita berupa pengajaran setiap hari tentang cara menyikat gigi yang benar dengan bahasa yang dimengerti anak tunagragahita selama dua minggu.

Penelitian dilakukan di asrama SLB Bhakti Luhur kota Malang. Penelitian ini tidak membatasi umur responden anak tunagrahita ringan karena keterbatasan jumlah responden anak tunagrahita ringan di asrama SLB Bhakti Luhur Malang. Perawat tunagrahita pada penelitian ini sebanyak 18 orang dengan pendidikan terakhir Sekolah Menengah Atas (SMA) dengan lama waktu merawat setiap anak tunagrahita 12-13 jam. Perawat dalam penelitian ini minimal 1 tahun telah merawat anak tunagrahita. Penarikan kesimpulan diambil dengan menggunakan $\mathrm{Uji} t$ Berpasangan (Paired $t$-Test) dengan tingkat signifikansi $a=5 \%$.

\section{HASIL PENELITIAN}

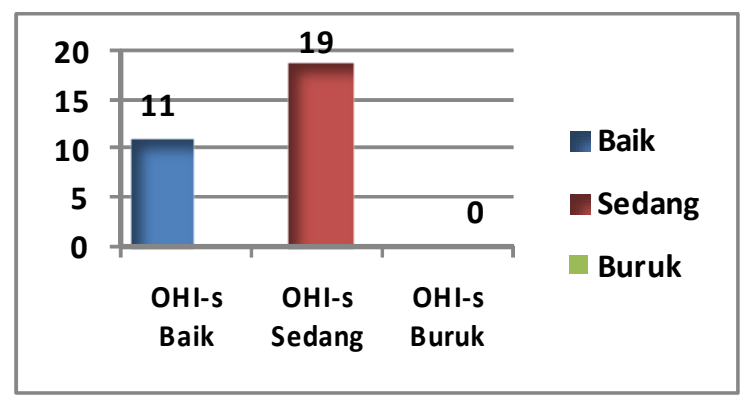

\section{Gambar 1. Distribusi Frekuensi}

\section{Responden $\mathrm{OHI}-\mathrm{s}$ sesudah Penyuluhan.}

Pada gambar 1 terlihat bahwa jumlah anak tuna grahita ringan yang diperiksa $O H I-S$ sebanyak 30 anak, sebanyak 19 responden anak tunagrahita ringan dalam penelitian ini nilai kebersihan gigi dan mulut $1,3-3,0$ berkategori cukup (63,33\%), sedangkan sebanyak 11 responden anak tunagrahita ringan dalam penelitian ini nilai kebersihan gigi dan mulut $0,0-1,2$ berkategori baik $(36,67 \%)$. Anak tunagrahita ringan yang diperiksa dalam penelitian ini berusia 6-15 tahun.

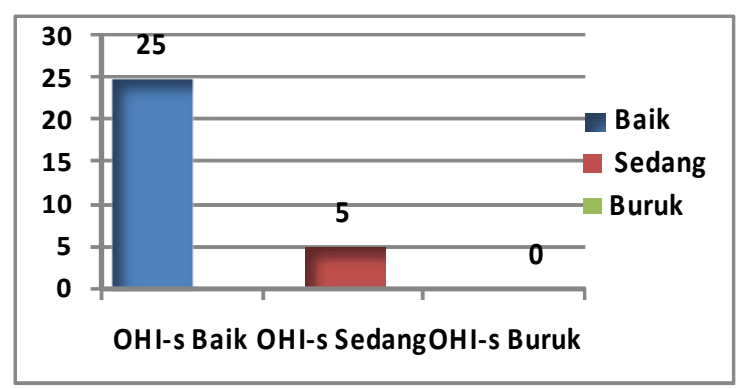

\section{Gambar 2. Distribusi Frekuensi Responden OHI-s Sesudah Penyuluhan.}

Pada gambar 2 terlihat bahwa sebanyak 25 responden anak tunagrahita ringan dalam penelitian ini nilai kebersihan gigi dan mulut 0,0-1,2 berkategori baik ( $83,33 \%)$, sedangkan sebanyak 5 responden anak tunagrahita ringan dalam penelitian ini nilai kebersihan gigi dan mulut 1,3 - 3,0 berkategori cukup $(16,67 \%)$.

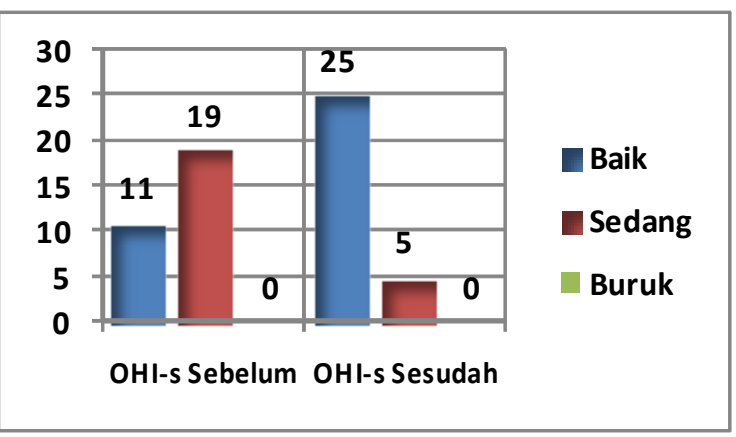

\section{Gambar 3. Distribusi Frekuensi}

\section{Responden $O H I-s$ Sebelum dan Sesudah}

\section{Penyuluhan.}

Pada gambar 3 terlihat bahwa pada pemeriksaan hari pertama $\mathrm{OHI}-\mathrm{s}$ anak 
tunagrahita ringan sebelum penyuluhan pada perawat tunagrahita sebanyak 19 responden berkategori cukup (63,33\%), sedangkan sebanyak 11 responden berkategori baik $(36,67 \%)$. Hasil berbeda pada saat pemeriksaan $\mathrm{OHI}-\mathrm{s}$ yang kedua anak tunagrahita ringan sesudah penyuluhan pada perawat tunagrahita sebanyak 25 responden berkategori baik $(83,33 \%)$, sedangkan sebanyak 5 responden berkategori cukup (16, $67 \%)$.

Dari analisis SPSS didapatkan hasil uji distribusi normalitas dengan nilai signifikansi $5 \%, p$-value $>a(0.05)$. Hasil uji normalitas nilai $p$-value masing-masing sebelum sebesar 0.913 dan sesudah sebesar 0.232 , yang menandakan bahwa variabel data hasil tingkat kebersihan gigi dan mulut anak tuna grahita dengan keterbelakangan mental ringan sebelum penyuluhan pada perawat tunagrahita mengikuti distribusi normal dan variabel data hasil tingkat kebersihan gigi dan mulut anak tunagrahita dengan keterbelakangan mental ringan sesudah penyuluhan pada perawat tunagrahita mengikuti distribusi normal.

Dengan data tentang tingkat kebersihan gigi dan mulut (OHI-s) anak tunagrahita dengan keterbelakangan mental ringan sebelum dan sesudah penyuluhan pada perawat tunagrahita mengandung unsur parametrik maka dalam mengambil keputusan dan kesimpulan menggunakan Paired Sampel t-Test.

Dari hasil uji t-Berpasangan didapatkan nilai mean $\mathrm{OHI}$-s anak tunagrahita sebelum penyuluhan pada perawat tunagrahita 1.38613 dan mean $O H I-s$ anak tunagrahita sesudah penyuluhan pada perawat tunagrahita
0.78340. Nilai sig. (2-tailed) < a $(0.05)$ yaitu $0.000<0.005$ yang berarti ada perbedaan $\mathrm{OHI}-\mathrm{s}$ anak tunagrahita dengan keterbelakangan mental ringan sebelum dilakukan penyuluhan pada perawat tunagrahita dengan $\mathrm{OHI}-\mathrm{s}$ anak tunagrahita dengan keterbelakangan mental ringan setelah dilakukan penyuluhan pada perawat tunagrahita di asrama SLB Bhakti Luhur Malang.

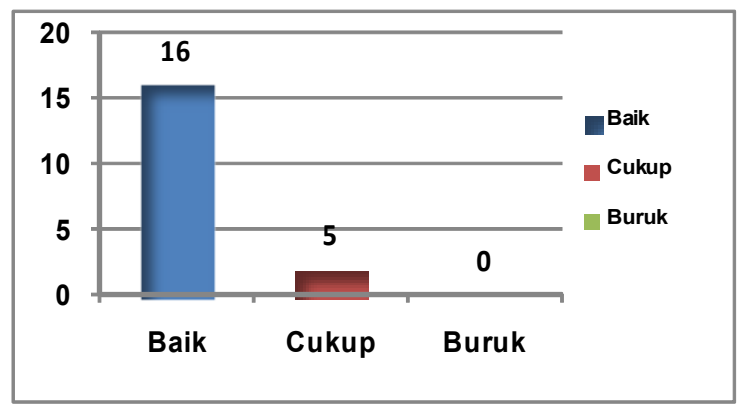

\section{Gambar 4. Diagram Pengukuran Keterampilan Kesehatan Gigi dan Mulut Perawat Tunagrahita.}

Penyuluhan pada perawat tunagrahita dilakukan dengan metode demontrasi yaitu memberikan informasi mengenai kesehatan gigi dan mulut dengan cara menunjukkan secara langsung obyeknya dengan disertai alat peraga yaitu phantom, sikat gigi serta menggunakan media poster. Materi pada penyuluhan ini meliputi teknik menyikat gigi yang baik dan benar serta cara menjaga kesehatan gigi dan mulut. Hasil penyuluhan pada perawat tunagrahita akan diukur dengan Check list dengan meminta perawat memperagakan kembali demonstrasi yang telah disuluhkan oleh peneliti. Sebelum penyuluhan, keterampilan menyikat gigi perawat tunagrahita cukup. Hal ini dikarenakan kurangnya pengetahuan dan 
pelatihan bagi perawat tunagrahita dalam menjaga kebersihan mulut.

Dari diagram batang keterampilan teknik menyikat gigi diatas terlihat bahwa sebanyak 16 responden perawat tunagrahita memiliki keterampilan menyikat gigi berkategori baik (88,89\%), sedangkan sebanyak 2 responden perawat tunagrahita memiliki keterampilan teknik menyikat gigi cukup (11,11\%). Setiap poin dalam check list penyuluhan diberikan skor 2 apabila dilakukan dan benar, skor 1 apabila dilakukan tapi salah, skor 0 apabila tidak dilakukan. ${ }^{10}$ Hasil check list demonstrasi responden yang telah dinilai tersebut dijumlahkan dan dibandingkan dengan skor tertinggi dikalikan $100 \%$. Interpretasi kategori baik apabila didapatkan hasil 76\%-100\%, kategori cukup apabila didapatkan hasil 56\%75\% dan kategori buruk apabila hasil kurang dari sama dengan $56 \%$.

\section{PEMBAHASAN}

Kebersihan mulut penting untuk kesehatan individu dengan kelainan intelektual atau perkembangan. Anak-anak dengan retardasi mental ringan memiliki tingkat kecerdasan tertinggi dibandingkan dengan derajat retardasi mental lainnya. Anak tunagrahita mengalami keterlambatan kemampuan kognitif (di bawah rata-rata normal) dan perilaku adaptif, akibatnya mereka tidak mampu merawat dirinya sendiri, termasuk merawat kesehatan gigi dan mulut. ${ }^{16}$ Orang dengan cacat intelektual seperti tunagrahita memiliki kebersihan mulut yang buruk dan tingkat keparahan lebih besar. Anak dengan tunagrahita mempunyai prevalensi lebih tinggi pada gingivitis dan periodontitis. ${ }^{12}$

Pada penelitian ini didapatkan tingkat kebersihan gigi dan mulut (OHI-s) anak tunagrahita ringan sebelum dilakukan penyuluhan pada perawat tunagrahita sebanyak 19 responden anak tunagrahita ringan nilai kebersihan gigi dan mulut 1,33,0 berkategori sedang $(63,33 \%)$, sedangkan sebanyak 11 responden anak tunagrahita ringan nilai kebersihan gigi dan mulut $0,0-1,2$ berkategori baik $(36,67 \%)$. Orang dengan retardasi mental memiliki hak yang sama untuk mendapatkan perawatan gigi, tetapi banyak dari mereka masih kesulitan untuk mendapatkannya. ${ }^{15}$ Kebersihan gigi dan mulut penting bagi anak tunagrahita ringan di asrama SLB Bhakti Luhur karena mereka memiliki keterbatasan sehingga memerlukan pendidikan khusus, bimbingan khusus oleh orang terdekat yaitu perawat tunagrahita untuk meningkatkan kualitas kesehatan gigi dan mulut. Anak tunagrahita memiliki keterbatasan intelegensi, keterbatasan sosial serta memiliki keterbatasan dalam penggunaan bahasa yang mereka gunakan. Keterbatasan tersebut disebabkan perbendaharaan yang kurang sehingga membutuhkan kata-kata yang sering mereka dengar dari orang disekitarnya yaitu perawat tunagrahita. ${ }^{18}$ Pada umumnya orang dengan kelainan perkembangan memiliki kesehatan mulut yang buruk serta memiliki prevalensi penyakit periodontal lebih tinggi dibanding dengan orang tanpa kelainan perkembangan. ${ }^{12}$ Pada penelitian ini terdapat beberapa anak tunagrahita yang mengalami peradangan atau pembengkakan pada gingiva oleh karena plak 
yang menempel pada gigi. Peradangan gingiva pada anak tuna grahita ringan yang tinggal di asrama disebabkan teknik menyikat gigi yang salah, frekuensi menyikat gigi anak tunagrahita yang berhubungan dengan terbentuknya plak, debris, kalkulus, serta jenis sikat gigi yang digunakan oleh anak tunagrahita ringan.

$\mathrm{OHI}-\mathrm{s}$ sebelum penyuluhan pada perawat tunagrahita menunjukkan sebagian besar responden anak tunagrahita ringan di asrama Bhakti Luhur Malang berkategori ringan sampai sedang. Hal ini disebabkan kebiasaan anak tunagrahita yang tinggal di asrama Bhakti Luhur memiliki perilaku adaptif untuk membersihkan gigi dan mulut oleh perawat tunagrahita di asrama Bhakti Luhur. Diet karbohidrat/makanan lebih terkontrol karena di asrama memiliki jam makan yang teratur sehingga konsumsi makanan pada anak tunagrahita lebih terkontrol. Pada umumnya orang dengan kelainan intelektual seperti retardasi mental memiliki kesehatan rongga mulut, oral hygiene dan penyakit periodontal yang lebih rendah dibanding dengan orang tanpa kelainan perkembangan. ${ }^{12}$ Selain penyuluhan, menyikat gigi juga memainkan peran yang penting dalam pencegahan penyakit mulut secara menyeluruh pada anak. Itulah sebabnya, menyikat gigi telah menjadi suatu aktivitas setiap hari yang penting bagi anak. ${ }^{18,19}$ Pada penelitian ini didapatkan tingkat kebersihan gigi dan mulut (OHI-s) anak tunagrahita ringan sesudah dilakukan penyuluhan pada perawat tunagrahita sebanyak 25 responden anak tunagrahita ringan dalam penelitian ini nilai kebersihan gigi dan mulut $0,0-1,2$ berkategori baik $(83,33 \%)$, sedangkan sebanyak 5 responden anak tunagrahita ringan dalam penelitian ini nilai kebersihan gigi dan mulut 1,3 - 3,0 berkategori cukup $(16,67 \%)$.

Anak tunagrahita ringan didefinisikan sebagai anak dengan kemampuan intelektual di bawah normal dan mempunyai IQ setara $55-70$ skala Weschler (WISC), mempunyai gangguan komunikasi, kesehatan, waktu luang, keamanan, sekolah, merawat diri, gangguan sosial, kesulitan mengerjakan pekerjaan rumah dan kesulitan bekerja; dan terjadi paa usia di bawah 18 tahun. ${ }^{20}$

Anak tunagrahita ringan memiliki pengetahuan akan kebersihan gigi dan mulut yang kurang serta kurang dalam keterampilan menyikat gigi yang baik dan benar, sehingga memerlukan orang yang dekat dengan anak tunagrahita untuk dapat membantu mengubah kebiasaannya. ${ }^{16,18}$ Sebelumnya mereka tidak biasa menyikat gigi setelah sarapan pagi dan malam sebelum tidur namun setelah dilakukan penyuluhan pada perawat tunagrahita, anak tunagrahita dapat mengubah kebiasaannya untuk menyikat gigi secara teratur yaitu setelah sarapan pagi dan sebelum tidur malam. Hal ini dapat diketahui dari kartu kontrol yang diberikan kepada perawat tunagrahita untuk mengisinya dan kepatuhan anak tunagrahita dalam membersihkan mulut. Teknik menyikat gigi adalah cara yang paling umum dianjurkan untuk membersihkan deposit lunak pada permukaan gigi dan gingiva dan merupakan tindakan preventif dalam keberhasilan dan kesehatan rongga mulut yang optimal untuk meningkatkan $\mathrm{OHI}$ $s$ anak tunagrahita ringan di asrama. Oleh karena itu, teknik menyikat gigi harus 
dilaksanakan secara aktif dan teratur. Menyikat gigi dapat menurunkan faktor resiko karies gigi. ${ }^{21}$ Metode yang digunakan adalah Teknik Roll karena teknik ini menekankan penempatan bulu sikat area batas gusi membentuk sudut 45 derajat serta mengarah ke akar gigi sehingga sebagian bulu sikat menekan gusi. Menyikat dari arah gusi ke permukaan gigi. Gerakan ini diulangi sebanyak 8-12 kali pada setiap permukaan agar tidak ada daerah yang terlewat. Metode ini digunakan dalam cara menyikat gigi anak tunagrahita ringan agar kotoran dapat keluar serta dapat membersihkan sela-sela gigi²

Pendidikan kesehatan mulut pada perawat dapat meningkatkan pengetahuan, keterampilan, kepatuhan kebersihan gigi dan mulut. Hal ini dapat menurunkan atau mencegah plak, dan penyakit periodontal. ${ }^{18,19}$ Terdapat perubahan yang signifikan dalam pengetahuan dan keterampilan antara sebelum dan sesudah promosi kesehatan gigi dan mulut anak tunagrahita ringan. Hasil uji Paired $t$-Test, hasil tersebut menunjukkan ada perbedaan $\mathrm{OHI}-\mathrm{s}$ anak tunagrahita dengan keterbelakangan mental ringan sebelum dilakukan penyuluhan pada perawat tunagrahita dengan $\mathrm{OHI}-\mathrm{s}$ anak tunagrahita dengan keterbelakangan mental ringan setelah dilakukan penyuluhan pada perawat tunagrahita di asrama SLB Bhakti Luhur Malang. Hal ini dibuktikan dari analisa didapatkan signifikansi $=0.000$ kurang dari signifikansi $a=0.05$. Dengan demikian penyuluhan teknik menyikat gigi dapat menurunkan $\mathrm{OHI}$-s anak tunagrahita ringan di asrama Bhakti Luhur Malang.
OHI-s anak tunagrahita dapat ditingkatkan dengan melakukan penyuluhan/edukasi cara menyikat gigi melalui orang terdekat anak tunagrahita yaitu perawat tunagrahita. ${ }^{16,18}$ Anak tunagrahita dengan keterbelakangan mental ringan sampai sedang memiliki peluang untuk mendapatkan kualitas hidup yang lebih baik melalui perilaku adaptif yang diajarkan secara intensif melalui orang-orang disekelilingnya. ${ }^{16,18} \quad$ Peran perawat berpengaruh terhadap tingkat kebersihan gigi dan mulut (OHI-s) anak tunagrahita ringan. Anak tunagrahita ringan dapat menyikat gigi sendiri setelah dilakukan penyuluhan pada perawat tunagrahita, mereka diberikan pembelajaran cara menjaga kesehatan gigi dan mulut dengan teknik menyikat gigi yang baik dan benar serta mereka yang memiliki keterbatasan fisik dibantu oleh perawat dalam menyikat gigi yang baik dan benar.

Terdapat perbedaan tingkat kebersihan gigi dan mulut ( $\mathrm{OHI}-\mathrm{s})$ anak tunagrahita dengan keterbelakangan mental ringan sebelum dilakukan penyuluhan pada perawat tunagrahita dengan $\mathrm{OHI}-\mathrm{s}$ anak tunagrahita dengan keterbelakangan mental ringan setelah dilakukan penyuluhan pada perawat tunagrahita di asrama SLB Bhakti Luhur Malang. Hal tersebut menandakan bahwa penyuluhan cara menyikat gigi pada perawat tunagrahita efektif. Tingkat kebersihan gigi dan mulut ( $O H I-s)$ anak tunagrahita ringan sebelum dan sesudah penyululuhan pada perawat tunagrahita di asrama Bhakti Luhur Malang umumnya sedang hingga ringan. Hal ini sejalan dengan penelitian yang dilakukan oleh Liu et al tahun 2014 yaitu status kesehatan mulut umumnya sedang hingga 
ringan, terutama pada anak keterbelakangan mental. ${ }^{19}$ Pada pemeriksaan hari pertama $O H I-s$ anak tunagrahita ringan sebelum penyuluhan pada perawat tunagrahita sebanyak 19 responden berkategori cukup $(63,33 \%)$, sedangkan sebanyak 11 responden berkategori baik (36,67\%). Hasil berbeda pada saat pemeriksaan $\mathrm{OHI}-\mathrm{s}$ yang kedua anak tunagrahita ringan sesudah penyuluhan pada perawat tunagrahita sebanyak 25 responden berkategori baik $(83,33 \%)$, sedangkan sebanyak 5 responden berkategori cukup (16,67\%). Hal ini menunjukkan terdapat peningkatan kebersihan mulut yang ditandai dengan turunnya $O H I-s$ anak tunagrahita ringan. Penurunan $\mathrm{OHI}-\mathrm{s}$ anak tunagrahita ringan disebabkan perilaku adaptif dalam menjaga kebersihan gigi dan mulut yang diajarkan oleh perawat tunagrahita di asrama Bhakti Luhur Malang.

Sebelum dilakukan penyuluhan cara menyikat gigi yang baik dan benar pada perawat tunagrahita keterampilan cara menyikat gigi yang baik dan benar perawat berkategori cukup, akan tetapi setelah dilakukan penyuluhan didapatkan sebanyak 16 responden perawat tunagrahita memiliki keterampilan teknik menyikat gigi baik $(88,89 \%)$, sedangkan sebanyak 2 responden perawat tunagrahita memiliki keterampilan cara menyikat gigi cukup $(11,11 \%)$. Perawat memegang peran yang penting terhadap kesehatan umum individu dengan cacat intelektual atau cacat perkembangan. Kebanyakan individu memiliki kekurangan ketangkasan fisik dan atau kekurangan kemampuan kognitif untuk menyelesaikan kebersihan mulut dan harus tergantung pada pengasuh mereka untuk membantu atau melakukannya untuk mereka. ${ }^{16,18}$ Anak dengan keterbelakangan mental membutuhkan perawatan yang khusus karena keterbatasan yang dimiliki. Kebersihan mulut yang kurang dan risiko penyakit periodontal dan karies gigi merupakan ciri-ciri yang umumnya ditemukan pada anak tunagrahita atau retardasi mental ${ }^{23}$. Oleh karena itu, dalam pemeliharaan kesehatan gigi dan mulut, anak-anak tunagrahita membutuhkan perawat untuk membantu menjaga kebersihan gigi dan mulut. Kebiasaan menyikat gigi pengasuh/perawat merupakan faktor yang berpengaruh terhadap kebiasaan menyikat pada anak-anak, sehingga peran pengasuh sangat menentukan dalam pertumbuhan dan berkembangan anak. Pengawasan dan bimbingan secara intensif dari pengasuh penderita retardasi mental (tunagrahita) dalam hal oral hygiene dapat menciptakan perilaku adaptif (perawatan oral hygiene) dari anak tersebut. ${ }^{16}$ Pengetahuan perawat tentang cara menjaga kesehatan gigi dan mulut merupakan hal yang penting diberi penyuluhan atau edukasi tentang cara menyikat gigi yang baik ${ }^{16,18}$. Pada umumnya, anak tunagrahita yang diasuh di rumah cenderung diberi makanan yang mengandung karbohidrat serta snack diantara waktu makan yang biasanya berupa makanan yang manis dan lengket, sedangkan kemampuan anak tunagrahita untuk memelihara kesehatan gigi dan mulutnya sangat kurang dan tidak diarahkan oleh orang tua untuk membersihkan giginya setelah mengkonsumsi makanan tersebut. ${ }^{24}$ Anak tuna grahita yang tinggal di asrama diberikan diet makanan biasanya 
dengan jam makan yang teratur sehingga konsumsi snack atau makanan yang manis lebih terkontrol. Sebagaimana diketahui bahwa sifat fisis makanan yang manis dan makanan yang bersifat lunak atau campuran semiliquid yang membutuhkan sedikit pengunyahan menyebabkan debris lebih mudah melekat di sekitar gigi dan bisa menyebabkan penumpukan bakteri serta memudahkan pembentukan karang gigi. ${ }^{1}$

Faktor yang mempengaruhi keberhasilan suatu penyuluhan kesehatan adalah pemilihan metode, alat bantu peraga atau media. ${ }^{25}$ Metode yang digunakan dari penelitian ini adalah demonstrasi dan alat bantu peraga yang digunakan dalam penelitian ini yaitu phantom penyuluhan, sikat gigi dan poster. Perawat diberikan penyuluhan kesehatan gigi dan mulut, diantaranya teknik menyikat gigi yang baik dan benar, dengan menggunakan alat bantu phantom penyuluhan, didemonstrasikan bagaimana cara menyikat gigi yang baik dan benar, kemudian perawat dinilai dengan menggunakan check list dan memperagakan cara menyikat gigi yang benar dengan alat bantu phantom.

Terdapat 18 responden perawat dengan pendidikan terakhir Sekolah Menengah Atas (SMA) dengan lama waktu merawatnya 12-13 jam per hari. Perawat yang dilibatkan dalam penelitian ini adalah yang telah merawat anak tunagrahita minimal 1 tahun. Hasil penelitian menunjukkan sebanyak 16 responden perawat tunagrahita memiliki keterampilan teknik menyikat gigi baik (88,89\%), sedangkan sebanyak 2 responden perawat tunagrahita memiliki keterampilan teknik menyikat gigi cukup $(11,11 \%)$. Perawat tunagrahita sangat berperan dalam melakukan pengkajian keperawatan, perencanaan, implementasi dan evaluasi pada anak tunagrahita ringan agar mereka tidak kesulitan dalam melakukan segala aktivitasnya. ${ }^{26} \mathrm{Hal}$ ini menunjukkan bahwa perawat tunagrahita yang memiliki pengetahuan teknik menyikat gigi yang baik dapat mengajarkan cara menjaga kebersihan gigi dan mulut yang baik dan benar serta dapat menurunkan tingkat kebersihan gigi dan mulut anak tunagrahita ringan sebelum dan sesudah penyuluhan pada perawat tunagrahita.

Dalam penelitian ini terbukti bahwa penyuluhan pada perawat tunagrahita adalah efektif karena dapat meningkatkan kebersihan mulut yang ditandai dengan turunnya nilai $O H I-s$ anak tunagrahita ringan sebelum dilakukan penyuluhan pada perawat tunagrahita dengan tingkat kebersihan gigi dan mulut (OHI-s) anak tunagrahita ringan sesudah dilakukan penyuluhan pada perawat tunagrahita.

\section{KESIMPULAN}

Anak tunagrahita ringan sebelum dilakukan penyuluhan pada perawat tunagrahita memiliki nilai $O H I-s$ berkategori sedang $(1,3-3,0)$ sebanyak $63,33 \%$ dan nilai $O H I-s$ berkategori baik $(0,0-1,2)$ sebanyak $36,67 \%$. Anak tunagrahita ringan sesudah dilakukan penyuluhan pada perawat tunagrahita memiliki nilai $O H I$-s berkategori baik $(0,0-1,2)$ sebanyak $83,33 \%$ dan nilai $O H I$-s berkategori sedang $(1,3-3,0)$ sebanyak $16,67 \%$. Terdapat perbedaan $\mathrm{OHI}-\mathrm{s}$ anak tunagrahita dengan keterbelakangan ringan sebelum dilakukan penyuluhan pada perawat tunagrahita dengan 
OHI-s anak tunagrahita dengan keterbelakangan mental ringan setelah dilakukan penyuluhan pada perawat tunagrahita di asrama SLB Bhakti Luhur Malang.

Sebagian besar perawat memiliki keterampilan menyikat gigi baik yaitu sebesar $(88,89 \%)$. Perawat mempunyai peran yang cukup penting dalam meningkatkan derajad kesehatan gigi dan mulut anak tunagrahita yang ditandai dengan dengan turunnya nilai $O H I$-s anak tunagrahita ringan sebelum dan sesudah penyuluhan kepada perawat tunagrahita.

\section{DAFTAR PUSTAKA}

1. Carranza F. 2006. Carranza's Clinical Periodontology. 10th ed. p137

2. American Dental Association. 2015. Brushing your teeth. [online] http://www.mouthhealthy.org/en/aztopics/b/brushing-your-teeth. 15 Maret 2017

3. Van Der Wijden, Fridus; Slot, Dagmar Else, RDH, MSC. 2013. How Effective is Toothbrushing? ABI/INFORM Collection

4. Praptiningsih $R$, Ningtyas $E$, Nurjanah N. 2010. Pengaruh Metode Menggosok Gigi Sebelum Makan Terhadap Kuantitas Bakteri dan PH Saliva. Dental Journal. 2008.

5. Hermina V. 2010. Efektivitas Metode Pengajaran Cara Menyikat Gigi Terhadap Penurunan Indeks Plak Anak Usia 3-5 Tahun. Dental Journal. volume 15 No. 1: 42-45.
6. Abdullah, Nandiyah. 2013. Mengenal Anak Berkebutuhan Khusus. Magistra No. 86 Th. XXV

7. Somantri, Sutjihati. 2006. Psikologi Anak Luar Biasa, Bandung: Rafika Aditama.

8. Schalock, RL dan Luckasson R. 2015. A systematic Approach to Subgroup Classification in Intellectual Dissability. Intellectual and Developmental Dissabilities. Vol. 53, No. 5, 358-366

9. American Association in Intellectual and Developmental Dissabilities. 2017. Definition of Intellectual Dissability. http://aaidd.org/intellectualdisability/definition/faqs-on-intellectualdisability\#.WM5FhYF97IU. Diakses tanggal 19 Maret 2017

10. Delphie, B. 2009. Pembelajaran Anak Berkebutuhan Khusus dalam Setting Pendidikan Inklusi Yogyakarta: PT. Intan Sejati Klaten.

11. Saragih, R. 2011. Peningkatan Kepedulian Terhadap Pemberdayaan Tunagrahita. http://www.kemsos.go.id/modules.php? name $=$ Content\&pa $=$ showpage $\&$ pid $=63$. diakses 19 Maret 2017

12. van Schrojenstein Lantman-de Valk, Henny M J; Walsh, Patricia Noonan. 2008. Managing health problems with people with Intellectual Dissabilities. BMJ : British Medical Journal (Online); London

13. Martens L, Marks L, Goffin G, Gizani S, Vinckier $F$ and Declerck D. 2000. Oral hygiene in 12-year-old disabled children in Flanders, Belgium, related to manual dexterity. Community Dent Oral Epidemiol; 28:73-80. Denmark

14. Tula, JJ. 2015. Pelayanan Penyandang Disabilitas Dalam Menggunakan Berbagai 
Sarana

Aksebilitas.

http://www.kemsos.go.id/modules.php?

name $=$ News\&file $=$ article $\&$ sid $=18765$.

Diakses tanggal 19 Maret 2017.

15. Kementrian Pendidikan dan Kebudayaan. 2015. Statistik Sekolah Luar Biasa (SLB) 2015/2016. Setjen Kemdikbud. Jakarta

16. Davies R; Bedi R; Scully C. 2000. Oral Health Care for Patients with Special Needs. British Medical Journal. London

17. Arikunto S. 2010. Prosedur Penelitian. Suatu Pendekatan Praktik. Jakarta: Rineka Cipta.

18. Fickert, NA dan Ross D. 2011. Effectiveness of a Caregiver Education Program on Providing Oral Care to Individuals with Intellectual and Developmental Disabilities. USA: University of Pittsburgh.

19. Zifeng Liu, Dongsheng Yu, Wei Luo, Jing Yang, Jiaxuan Lu, Shuo Gao, Wenqing Li, Wei Zhao. 2014. Impact of Oral Health Behaviors on Dental Caries in Children with Intellectual Disabilities in Guangzhou, China. Int. J. Environ. Res. Public Health 2014, 11, 11015-11027.

20. -. 2015. Mental retardation. http://www.psyweb.com/Mdisord/jsp/men ret.jsp; diakses 21 Maret 2017

21. Slot $D$, Wiggelinkhuizen $L$, Rosema N, Van der Weijden G. The efficacy of manual toothbrushes following a brushing exercise: a systematic review. 2012. International Journal of Dental Hygiene; 10:187-97

22. Pratiwi, P.D,. 2013. Perbandingan Wayang BOGI (Boneka Gigi) dan Fliphchart Sebagai Media Promosi
Kesehatan Gigi dan Mulut Pada Anak Tunagrahita Ringan. Dental Public Health Journal. Surabaya: Universitas Airlangga.

23. O'Keefe E. 2010. Oral Health of Patients with Intellectual Disabilities. Scotland,UK: Department of Public Health, NHS Fife, Leven.

24. Patrick L. Anders, DDS, MPH, Elaine L. Davis, PhD. 2010. Oral Health of Patients with Intellectual Disabilities: A Systematic Review. State University of New York at Buffalo School of Dental Medicine Buffalo, New York: Pec Care Dentist 30(3): 110117.

25. Herijulianti E, Indriani TS, Artini S. 2001. Pendidikan Kesehatan Gigi. EGC: Jakarta

26. Hamid AY. 2008. Asuhan Keperawatan Kesehatan Jiwa Bunga Rimpai. Jakarta: EGC. 